\title{
Distribution of Organochlorine Pesticides in Urban Soil from Beijing, People's Republic of China
}

\author{
X. H. Li, ${ }^{1}$ L. L. Ma, ${ }^{1}$ X. F. Liu, ${ }^{1}$ S. Fu, ${ }^{1}$ H. X. Cheng, ${ }^{2}$ X. B. Xu ${ }^{1}$ \\ ${ }^{1}$ State Key Laboratory of Research, Center for Eco-Environmental Sciences, The \\ Chinese Academy of Sciences, Post Office Box 2871, Beijing 100085, People's \\ Republic of China \\ ${ }_{2}^{2}$ Institute of Geochemical and Geophysical Exploration, Beijing 065000, People's \\ Republic of China
}

Received: 17 December 2004/Accepted: 16 February 2005

Organochlorine pesticides (OCPs) are a group of compounds of great environmental concern because of their high toxicity and persistence, bioaccumulation to non-target organism in the ecosystem (Jones et al., 1999). In China, OCPs used to be the most important pesticides, produced to enhance agricultural yields, forestry and public health from the 1960 s to $1980 \mathrm{~s}$ (Li et al., 1998). In 1983, the Chinese government banned the production and usage of technical $\mathrm{HCH}$, but lindane (about 99\% $\quad \mathrm{\gamma}-\mathrm{HCH}$ ) is still allowable to use in a restricted way ( $\mathrm{Li}$, et al., 2001). DDT has been officially restricted to campaigns for vector control or as the intermediate of dicofol. HCB was used as an industrial chemical and was also by-product of some industrial chlorination processes.

The rapid development of Beijing, as the capital with a population of 13819000 . has resulted in significant stress to Beijng environments. The city area occupies a surface of $16807 \mathrm{~km}^{2}$, with more than $400 \mathrm{~km}^{2}$ is classed as urban areas. As urban areas are densely populated, the environmental quality of urban soil is closely related to human health. Recently some studies revealed that the atmosphere in the urban area of Beijing contained HCHs and DDTs (Wu et al., 2003; Xu et al., 2003). Zhang et al. (2004) reported that the water in Tonghui River, which is a main urban drainage river for Beijing, was moderately polluted by organochlorine pesticides. Generally, the soil was considered as the ultimate sink for OCPs. OCPs in soil can enter into the atmosphere by evaporation and migrate into water by rain et al, thus causing direct or indirect exposure of humans to the organic pollutants (Finizion et al., 1998; Waite et al., 1995). The above prompted us to carry out the monitoring of such pollutants in the urban soil, especially for Beijing, which had ever produced and used large amount of HCHs and DDTs. 


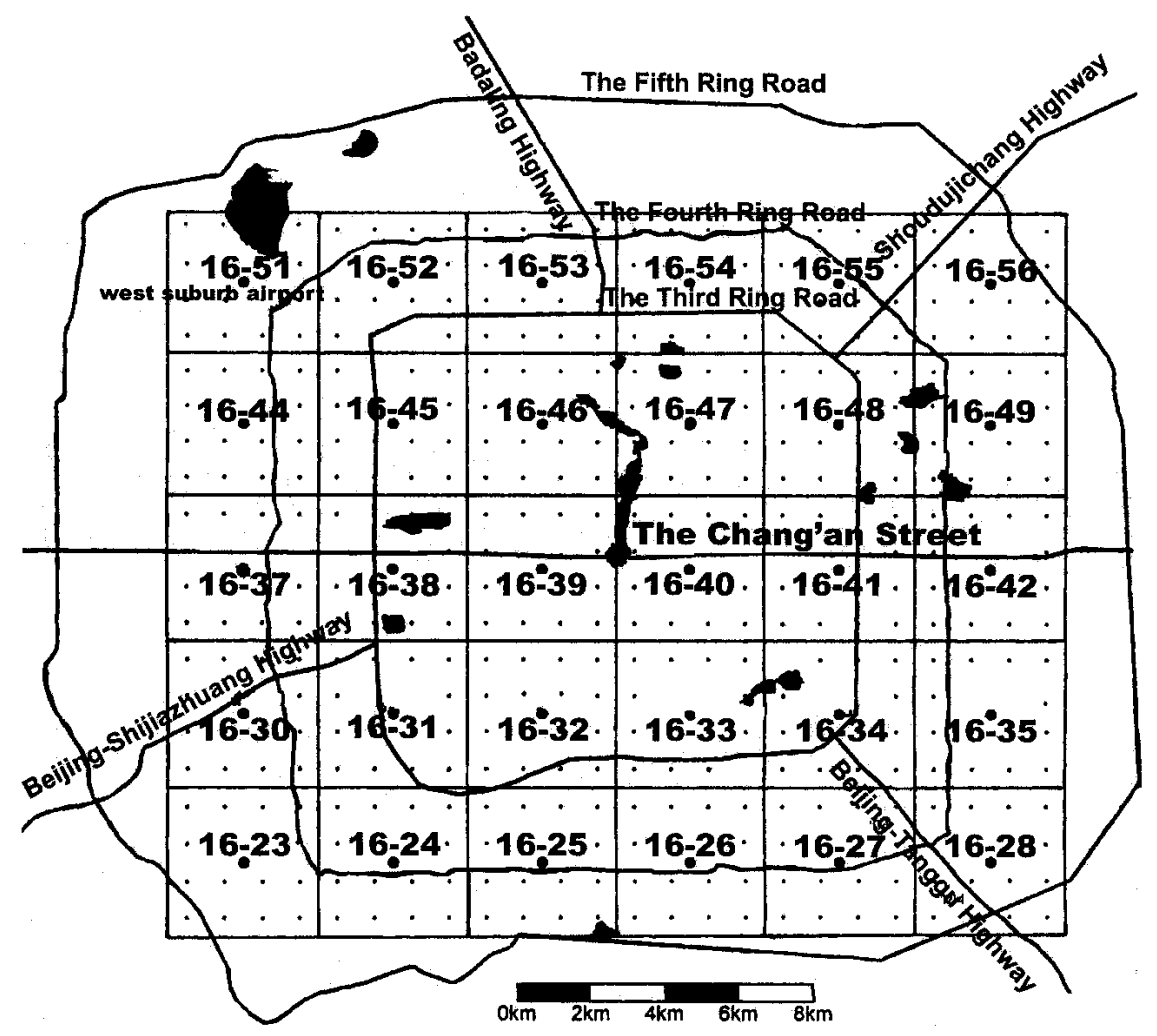

Figure 1. Geographic location of samples sites

The aim of the present study is to explore the current pollution status and accumulation feature of organochlorine pesticides in the topsoil of urban area of Beijing, to investigate the previous and current possible inputs of the OCPs pollutants. The information will be useful for evaluating the soil environmental quality of the metropolis, for the management and remediation of urban soil.

\section{MATERIALS AND METHODS}

Stock solutions of eight organochlorine pesticides including $\alpha-\mathrm{HCH}, \beta-\mathrm{HCH}$, $\gamma-\mathrm{HCH}, \delta-\mathrm{HCH}, \mathrm{p}, \mathrm{p}^{\prime}$-DDT, p,p'-DDE, p,p'-DDD, HCB were obtained from National Research Center for Certified Reference Materials of China at a concentration of $100 \mathrm{mg} / \mathrm{L}$ and further diluted to obtain the desired concentration. 2,4,5,6-tetrachloro- $m$-xylene was used as surrogate. All solvents were of analytical purity (Beijing Chemical Factory, China) and were redistilled in all-glass system before use. Florisil (60-100 mesh) were purchased from Supelco (Bellfonte, USA) and was activated in drying oven at $130{ }^{\circ} \mathrm{C}$ for $16 \mathrm{~h}$. 
Anhydrous sodium sulfate (Beijing Chemical Factory, China) was heated at 600 ${ }^{\circ} \mathrm{C}$ for $12 \mathrm{~h}$.

The urban area of the whole Beijing city was surrounded by five ring roads. 30 sites at different locations within the five Ring Roads of Beijing city were sampled in the fall in 2003 . The study area was divided into regular grids of $4 \times 4$ $\mathrm{km}^{2}$, within which the topsoil samples $(5-30 \mathrm{~cm})$ were collected. Each of the composite soil samples was made of 16 sub-samples obtained in a $1 \times 1 \mathrm{~km}^{2}$ grid using a stainless steel hand auger. The detailed sampling locations are shown in Figure 1. The soil was air-dried at room temperature, thoroughly mixed, sieved to 30 mesh and stored in glass bottles at $-4^{\circ} \mathrm{C}$ until further processing. The remaining water content in the soil was determined gravimetrically after drying individual sample in an oven at $105{ }^{\circ} \mathrm{C}$ for $12 \mathrm{~h}$. All the results were reported as dried weight.

$5 \mathrm{~g}$ of soil was ground with anhydrous sodium sulfate into free flowing powder. The sample was ultrasonically extracted in centrifuge tube with $30 \mathrm{~mL}$ of $1 / 1(\mathrm{v} / \mathrm{v})$ acetone/hexane for $5 \mathrm{~min}$ and then the extact was separated by centrifugation. The process was repeated for three times. The solvents were combined and were evaporated by rotary evaporator with a reduce pressure at $35{ }^{\circ} \mathrm{C}$ water bath, then hexane was added as solvent. The concentrated extract was transferred to chromatograph column ( $30 \mathrm{~cm} \times 10 \mathrm{~mm}$ I.D.) containig $5 \mathrm{~g}$ activated Florisil and $1 \mathrm{~g}$ of anhydrous sodium sulfate on the column top. The Florisil was soaked in hexane and was filled in the column. The concentrated extract was transferred to the column top and was eluted by $50 \mathrm{~mL} n$-hexane/diethyl-ether $(9 / 1)$. The washing solvent was evaporated by rotary evaporator, then was adjusted to $0.2 \mathrm{~mL}$ for GC analysis.

The identification and quantification of organochlorine pesticides were carried out with an Agilent 6890 gas chromatograph equipped with micro-cell ${ }^{63} \mathrm{Ni}$ electron capture detector $(\mu-E C D)$. The separation was performed on a fused silica capillary column (HP-5, $30 \mathrm{~m} \times 0.25 \mathrm{~mm}$ I.D., and $0.25 \mu \mathrm{m}$ film thickness). The carrier gas was nitrogen with a flow of $0.7 \mathrm{~mL} / \mathrm{min}$. The injector and detector temperature were $225{ }^{\circ} \mathrm{C}$ and $310^{\circ} \mathrm{C}$, respectively. The $\mathrm{GC}$ oven temperature was programmed as follows: initial temperature $100{ }^{\circ} \mathrm{C}$ held for $2 \mathrm{~min}$, increased to $160{ }^{\circ} \mathrm{C}$ at a rate of $10{ }^{\circ} \mathrm{C} / \mathrm{min}$, then increased to $230{ }^{\circ} \mathrm{C}$ at a rate of $4{ }^{\circ} \mathrm{C} / \mathrm{min}$, followed by $10{ }^{\circ} \mathrm{C} / \mathrm{min}$ ascent to $280{ }^{\circ} \mathrm{C}$, maintained for $10 \mathrm{~min} .1 \mu \mathrm{L}$ of sample was injected in splitless mode. Peak identification of organochlorine pesticide was made by comparison of retention times with corresponding standards(see Figure 2). 

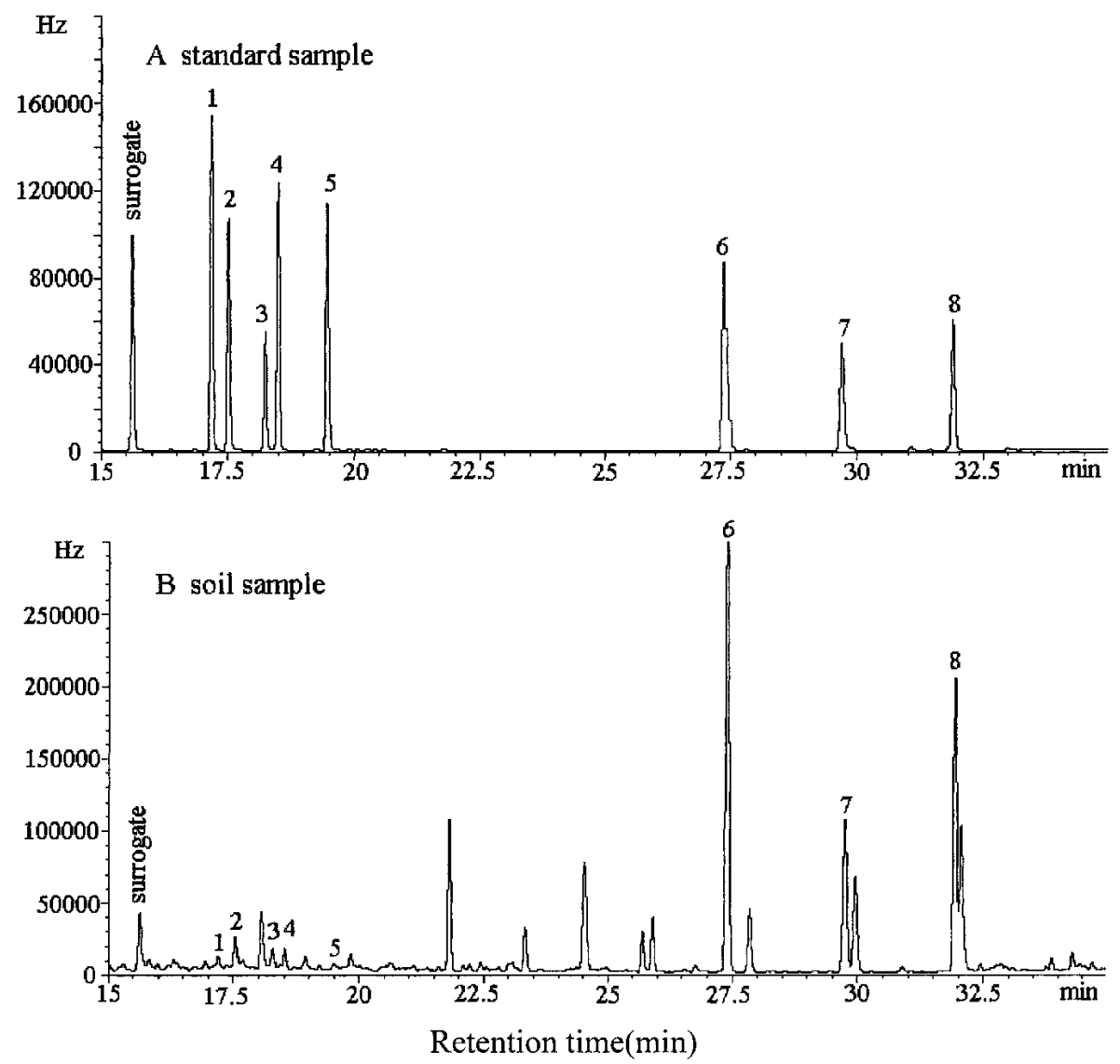

Figure 2. Chromatography of OCPs (A) standard sample; (B) soil sample; Peak numbers correspond to: (1) $\alpha-\mathrm{HCH}$, (2) $\mathrm{HCB}$, (3) $\beta-\mathrm{HCH}$, (4) $\gamma-\mathrm{HCH}$, (5) $\delta$ -HCH, (6) p, p'-DDE, (7) p, p'-DDD, (8) p,p'-DDT.

Quality assurance criteria for these compound analyses were based on the measures of soil samples from underground about $20 \mathrm{~m}$ depth. The limit of detection (LOD) for OCPs as three times response of signal-to-noise in blank sample, ranged from 0.05 to $0.15 \mathrm{ng} / \mathrm{g}$. The average recovery experiments in triple were done by spiked known concentration standards in soil and were $87 \pm 7 \%$ for DDTs, $82 \pm 4 \%$ for $\mathrm{HCHs}$ and $94 \pm 6 \%$ for $\mathrm{HCB}$.

\section{RESULTS AND DISCISSION}

The concentrations of OCPs residues in each sample analyzed in this study are shown in Figure 3. The $\sum$ DDT (equivalent sum of pp'-DDE, pp'-DDD and $\mathrm{pp}^{\prime}$-DDT) content had a mean of $56.78 \pm 55.42 \mathrm{ng} / \mathrm{g}$ of the dry weight and ranged 

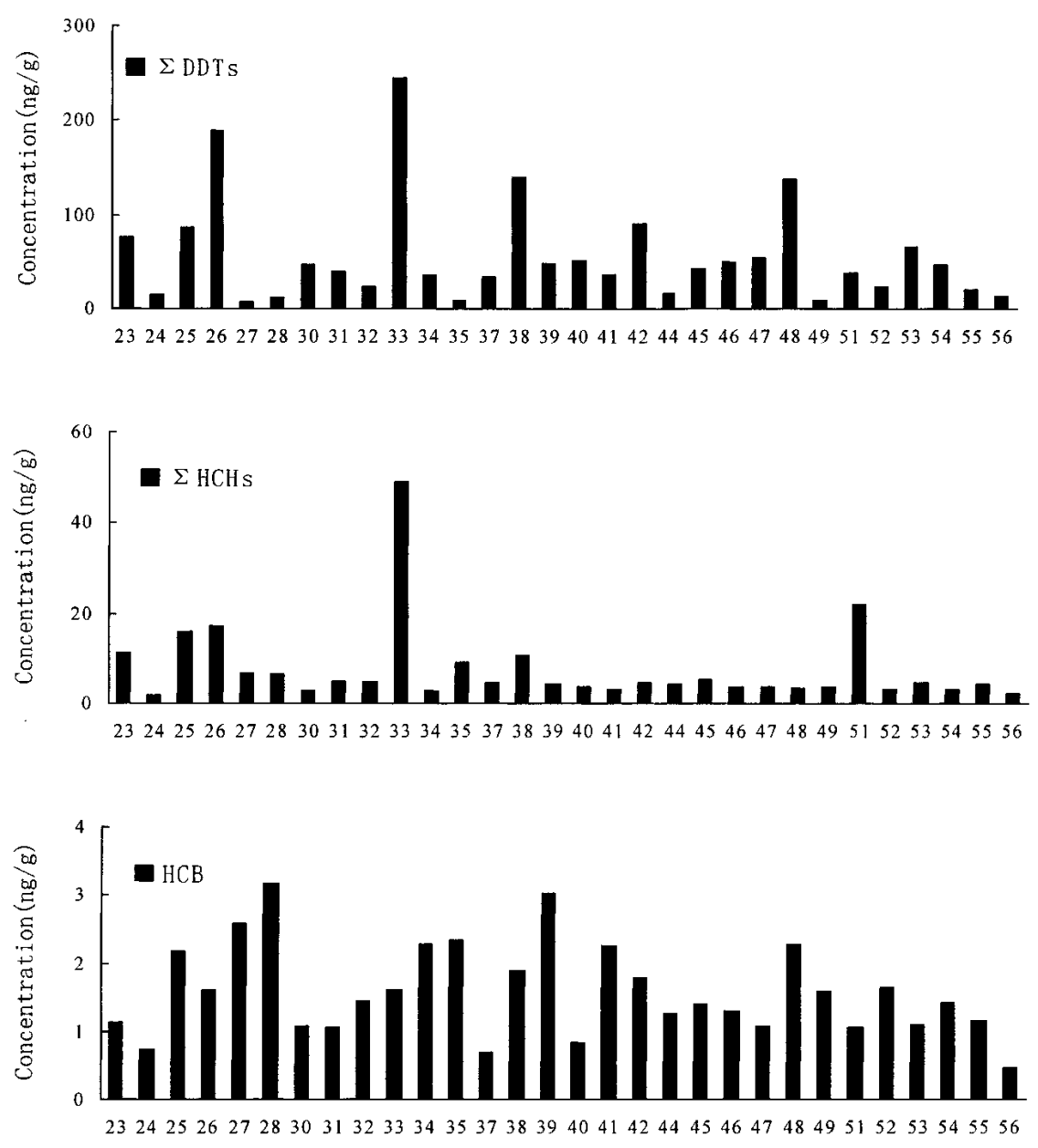

Samples sites

Figure 3. Concentration of DDTs, HCHs and HCB in urban soil from Beijing

from 7.24-244.37 ng/g with $41.31 \mathrm{ng} / \mathrm{g}$ as media. The concentrations of DDTs were in general in order $\mathrm{pp}^{\prime}-\mathrm{DDE}>\mathrm{pp}$-DDT $>\mathrm{pp}^{\prime}-\mathrm{DDD}$. The $\mathrm{pp}^{\prime}$-DDE was the major metabolite and it contributed about $61.0 \%$ of the EDDT. The concentrations of DDTs were slightly more than that of DDE concentrations only in three samples (site 33, 26 and 42). Since level of DDT in the natural environment will decrease with time and the major metabolite is expected to be DDE and DDD (Cooke et al., 1982), the ratio of (pp'-DDE+ $\mathrm{pp}^{\prime}$-DDD) /pp'-DDT may be used to monitor the new input of DDT in the environment. In this study, the ratio of ( $\mathrm{pp}^{\prime}-\mathrm{DDE}+\mathrm{pp}$-DDD)/pp'-DDT was found from $0.81-7.79 \mathrm{ng} / \mathrm{g}$ with $1.81 \mathrm{ng} / \mathrm{g}$ as median and the ratios of only three soil samples were less than 1 . The predominance indicated extensive contamination of DDT occurred in the past. 
However, high concentration of DDT in some sites might indicate that there seemed some new input of DDT recently. In comparison with the soil around Beijing, the $\sum$ DDT level in this survey was slightly higher than that in soil around Beijing Guanting Reservoir (nd-176.01 ng/g, Hong et al., 2004), was lower than that in the greenhouse soils from Beijing suburbs $(64.44 \pm 30.36 \mathrm{ng} / \mathrm{g}$; Ma et al., 2003) and was comparable to soil in Tianjing area (Gong et al., 2004a). Compared the levels of $\sum$ DDT with the other urban areas abroad, value of concentration was lower than that in Romanian (113.1 $\pm 151.8 \mathrm{ng} / \mathrm{g}$; Covaci et al., 2001), in

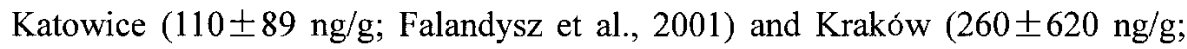
Falandysz et al., 2001). However, it was higher than that in India (3.4-190 ng/g; Kawano et al., 1992).

All the samples had presented the residues of $\mathrm{HCH}$. The $\Sigma \mathrm{HCH}$ content (equivalent sum of $\alpha-+\beta-+\gamma-+\delta-\mathrm{HCH}$ ) had a mean of $7.53 \pm 9.15 \mathrm{ng} / \mathrm{g}$ and ranged from $1.83-48.83 \mathrm{ng} / \mathrm{g}$ with $4.43 \mathrm{ng} / \mathrm{g}$ as media. $\beta-\mathrm{HCH}$ was the major composition and contributed about $54 \%$ of the $\sum \mathrm{HCH}$. High concentrations of $\beta-\mathrm{HCH}$ meant that there was a significant historical usage of the technical $\mathrm{HCH}$ in the research area. The $\alpha-/ \gamma-\mathrm{HCH}$ has been used to monitor the source and use history of HCHs. The ratio of $\alpha / \gamma-\mathrm{HCH}$ would be in the range of 4.64-5.83 for the technical $\mathrm{HCH}$ and nearly zero for lindane (Zhang et al., 2004). In this study, $\alpha-/ \gamma-\mathrm{HCH}$ ratios were in the range of $0-1.25 \mathrm{ng} / \mathrm{g}(0.36 \mathrm{ng} / \mathrm{g}$ as median) and most were less than 0.8 , and $\alpha / \gamma-\mathrm{HCH}>1$ was only observed in samples from site 38 (1.25) and site 32 (1.01). This result indicated that long time has elapsed since the use of HCHs in the area or/and implied the presence of a possible emission source of lindane, which was used in a restricted way in China. In comparison with the soil study around Beijing, HCHs level in this study was significantly higher than that in soil around Beijing Guanting Reservoir (nd-19.23 ng/g, Hong et al., 2004) and was lower than that in the greenhouse soils from Beijing suburbs (15.77 \pm 6.0 ng/g; Ma et al., 2003) and was much lower than that in Tianjing urban area (45.8 $\mathrm{ng} / \mathrm{g}$; Gong et al., 2004b). Compared with the other urban areas abroad, the value of concentration was lower than that in Romanian $(29.17 \pm 27.14 \mathrm{ng} / \mathrm{g}$; Covaci et al., 2001), and Kraków (11 $\pm 29 \mathrm{ng} / \mathrm{g}$; Falandysz et al., 2001). However, it was higher than urban soil in India (in the range of 0.55-27 ng/g; Kawano et al., 1992) and in Katowice (5.9 $\pm 3.3 \mathrm{ng} / \mathrm{g}$; Falandysz et al., 2001).

HCB has very strong environmental persistence and toxicity. It can be transported in a long range and be significant accumulated in biota (Muir et al., 1993). In our study, the concentration of HCB was in the range of $0.46-3.17 \mathrm{ng} / \mathrm{g}$ with a mean of $1.58 \pm 0.68 \mathrm{ng} / \mathrm{g}$. $\mathrm{HCB}$ in all soil samples was detected out and the highest concentration appeared in site $28(3.17 \mathrm{ng} / \mathrm{g})$. The mean value of HCB level in this study was similar to that in Romanian $(1.9 \pm 2.1 \mathrm{ng} / \mathrm{g}$; Covaci et al., 2001) and 
Kraków (1.7 $2.6 \mathrm{ng} / \mathrm{g}$; Falandysz et al., 2001), but was lower than that in Katowice (6.4 $\pm 9.6 \mathrm{ng} / \mathrm{g}$; Falandysz et al., 2001).

In the terms of data obtained, the total pesticides concentration in soil varied from 14.27 to $294.78 \mathrm{ng} / \mathrm{g}$ dry weight with a mean value of $50.08 \mathrm{ng} / \mathrm{g}$. The highest concentration was found in site 33 . The DDT was major pollutant in urban soil of Beijing and was obviously more abundant than HCHs and HCB reflecting the use of the former insecticide in relatively large amounts for vector control in Beijing. According to the guidelines of Chinese environmental quality standard for soil (GB 15618-1995), the maximum allowable concentration of class I soil was $<50$ $\mathrm{ng} / \mathrm{g}$, and that of class II soil was $<500 \mathrm{ng} / \mathrm{g}$ and that of classIII soil was $<1000$ $\mathrm{ng} / \mathrm{g}$ for both $\sum \mathrm{HCH}$ and $\sum D D T$, respectively. The levels of $\sum \mathrm{HCH}$ here in all the soil samples were beneath the criteria of class I.The levels of $\Sigma D D T$ in all soil samples was beneath the criteria of class II and twenty to thirty soil samples were beneath the criteria of class I. In short, our study showed that the levels of $\sum H C H$ and $\sum$ DDT in all soil samples of the urban area in Beijing were fitted with the national criteria of class II. However, the high concentrations residues of 2 DDT and $\Sigma \mathrm{HCH}$ were found in sites 33 and 26 and this might contribute to this fact that some pesticide and/or chemical industry factories had ever been located in the areas in the past. These sites should be paid close attention.

This work revealed the soil contamination information by DDTs, HCHs and HCB residues in urban area of Beijing. It extends ours understanding of the current OCPs contamination status in the metropolis of China. Concentrations of OCPs at all sites did not exceed the Chinese guideline values for soil. Although the contamination levels detected here weren't high enough to cause acute effects, they could have negative impacts on the local atmosphere, aquatic ecosystems in a long term, especially for several sites with higher concentrations of OCPs.

Acknowledgments. This work was supported by Major State Basic Research Program of China (No.G 1999045707) and the Knowledge Innovation Program of the Chinese Academy of Sciences (RCEES 9902, 9906).

\section{REFERENCES}

Covaci A, Hura C, Schepens P (2001) Selected persistent organochlorine pollutants in Romania. Sci Total Environ 280:143-152

Falandysz J, Brudnowska B, Kawano M, Wakimoto T (2001) Polychlorinated biphenyls and organochlorine pesticides in soils from the southern part of Poland. Arch Environ Contam Toxicol 40:173-178

Finizion A, Bidleman TF, Szeto SY (1998) Emission of chiral pesticides from an 
agricultural soil in the fraser valley, British Columbia. Chemosphere 36 : 345-355

Gong ZM, Tao S, Xu FL, Dawson R, Liu WX, Cui YH, Cao J, Wang XJ, Shen WR, Zhang WJ, Qing BP, Sun R (2004a) Level and distribution of DDT in surface soils from Tianjin, China. Chemosphere 54:1247-1253

Gong ZM, Xu FL, Dawson R, Cao J, Liu WX, Li BG, Shen WR, Zhang WJ, Qing BP, Sun R (2004b) Residues of hexachlorocyclohexane isomers and their distribution characteristics in soils in the Tianjin area, China. Arch Environ Contam Toxicol 46: 432-437

Hong Z, Yonglong L, Tieyu W, Yajuan S (2004) Accumulation features of organochlorine pesticides residues in soils around Beijing Guanting Reservoir. Bull Environ Contam Toxicol 72: 954-961

Jones KC, Voogt P.de (1999) Persistent organic pollutants (POPs): state of the science. Environ Pollut 100: 209-221

Kawano M, Ramesh A, Thao VD, Tatsukawa R (1992) Persistent organochlorine insecticide residues in some paddy, upland and urban soils of India. Int $\mathrm{J}$ Anal Chem 48: 163-174

Li YF, Cai DJ, Singh A (1998) Hexachlorocyclohexane use trends in China and their impact on the environment. Arch Environ Contam Toxicol 35:688-697

Li, YF, Cai DG, Shan ZJ, Zhu ZL (2001) Gridded usage inventories of technical hexachlorocyclohexane and lindane for China with $1 / 6^{\circ}$ latitude by $1 / 4^{\circ}$ longitude resoulution. Arch Environ Contam Toxicol 41: 261-266

Ma LL, Chu SG, Xu XB (2003) Organic contamination in the greenhouse soils from Beijing suburbs, China. J Environ Monit 5: 786-790

Muir DCG, Segstro MD, Welbourn PM, Toom D, Eisenreich SJ, Macdonald CR, Whelpdale DM (1993) Patterns of accumulation of airborne organochlorine contaminants in lichens from the Upper Great Lakes Region of Ontario. Environ Sci Technol 27: 1201-1210

Waite DT, Grover R, Westcott ND, Irvine DG, Kerr LA, Sommerstad H (1995) Atmospheric deposition of pesticides in a small southern Saskatchewan watershed. Environ Toxicol Chem 14:117-1175

Wu SP, Cao J, Li BG, Xu FL, Shen WR, Han BP, Sun R, Tao S (2003) Residues and distribution of organochlorine pesticides in airborne particles of different sizes from urban areas. Res of Environ Sci 16: 36-39(in Chinese)

Xu DD, Deng LL, Li SH, Chai ZF, Mao XY (2003) Studies on the organohalogens pollutant in pine needles in Beijing. China Environ Sci 23: 315-320 (in Chinese)

Zhang ZL, Huang J, Yu G, Hong HS (2004) Occurrence of PAHs, PCBs and organochlorine pesticides in Tonghui River of Beijing, China. Environ Pollut 130: $249-261$ 